\title{
Comparison of Course Completion and Student Performance through Online and Traditional Courses
}
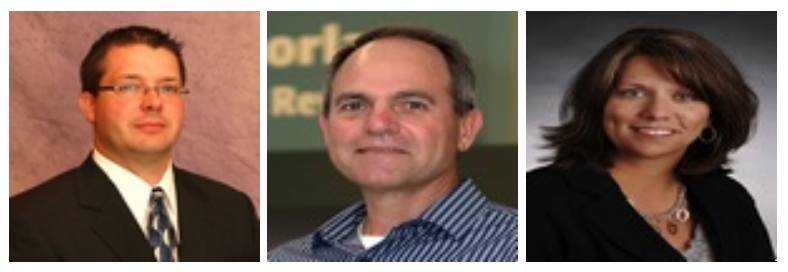

Wayne Atchley ${ }^{1}$, Gary Wingenbach 2 , and Cindy Akers ${ }^{3}$

${ }^{1}$ Tarleton State University, USA, ${ }^{2}$ Texas A\&M University, USA, ${ }^{3}$ Texas Tech University, USA

\section{Abstract}

Enrollment in online courses has outpaced overall university enrollment for the past several years. The growth of online courses does not appear to be slowing. The purpose of this study was to compare course completion and student academic performance between online and traditional courses. Archival data from the host university student records system was collected using the Structured Query Language. Descriptive statistics were used to analyze student characteristics. Chi-square analysis was used to determine if statistically significant differences existed between students enrolled in online and traditional courses when comparing course completion and academic performance. Analysis found statistically significant differences existed in both course completion and academic performance for students enrolled in online versus traditional courses. Additional analysis indicated statistically significant differences existed in course completion by course discipline.

Keywords: Online education; student performance; student retention 


\section{Introduction}

In the fall of 2007, more than 17.9 million students were enrolled in degree-granting, postsecondary institutions. Of those students, more than 3.9 million were enrolled in one or more online courses. Online enrollments represented $21.9 \%$ of total enrollments. From fall 2002 to fall 2007, online enrollments grew at a compound annual growth rate of 19.7\% from 1.6 million to more than 3.9 million (Allen \& Seaman, 2008). With the growth of online course enrollments, questions have been asked about course completion and student performance in online courses compared to traditional, face-toface courses.

Russel (2001) compiled an annotated bibliography of 355 research reports that examined differences in student outcomes between online and traditional courses. The majority of research revealed no statistically significant difference in student outcomes based on delivery mode. However, recent research on course completion and performance has been inconsistent. Brady (2001), Carr (2000), and Simpson (2003) found that course completion was generally lower in online courses when compared to traditional courses. Roach (2002) found that some institutions reported equal or higher course completion rates in online courses when compared to traditional courses. The problem this research will address is that further evidence is needed regarding student success measures in online instruction as opposed to classroom delivery.

Grouth in online course enrollments is clear and many researchers agree that the future of higher education is tied to some form of online course delivery (Berger \& Lyon, 2005; Harasim, 2000; Palloff \& Pratt, 2003). Are course completion rates significantly different between online and traditional courses? Is a student's academic performance independent of the course delivery method? These questions are important to administrators tasked with maintaining the competitive and economic future of their respective universities and are the focus of this research.

\section{Formula Funding}

Texas public universities receive flexible, discretionary state funds based primarily on the formula funding calculation under the direction of the Texas Higher Education Coordinating Board (THECB). Of all the funds appropriated directly to Texas public universities, more than $62 \%$ comes from formula funding. The primary source of formula funding is generated by the instruction and operations formula. This formula is based on semester credit hours applied to a cost matrix identifying weights based on level of instruction (lower division, upper division, master, doctoral, or professional) and discipline (liberal arts, science, fine arts, etc.). The other formulas, Teaching Experience, Small Institution Supplement, and Infrastructure, also include semester credit hours, but total less than $25 \%$ of formula funding for most universities (THECB, 2008). Current formula funding is based on the $12^{\text {th }}$ day of class enrollments and does not take into account students who drop courses during the semester. 
In the state of Texas, course completion rates have become important with regards to funding. The THECB recommended a shift in formula funding for the 2010-2011 biennium. The proposal would change the funding formula from using attempted to completed semester credit hours (THECB, 2008). With the continued growth of online education and the proposed shift in funding, course completion rates in online courses became increasingly important to administrators at Texas public universities.

Another State of Texas rule for public university funding related to the number of times a student can repeat a course, commonly referred to as the "Three-Peat" rule (Texas Administrative Code [TAC], Title 19, Part 1, Rule 13.105, 2005). This rule has an impact on the student and university. The three-peat rule states that "Institutions shall not submit for formula funding any hours for a course that is the same or substantially similar to a course that the student previously attempted for two or more times at the same institution" ([TAC], Title 19, Part 1, Rule 13.105, 2005). In order for the university to compensate for the loss of funding, the student can be charged full out-of-state tuition cost for any course impacted by the three-peat rule. The three-peat rule increased the importance of student academic performance to avoid potential loss of state funding for the course and possible increased financial burden on the student.

\section{Course Completion}

Research on course completion rates between online and traditional course delivery has been mixed (Carr, 2000). Several studies showed differences existed in course completion rates between online courses and traditional, face-to-face courses (McLaren, 2004; Paden, 2006; Roach, 2002). Waschull (2001) found that online course completion rates were not significantly different from traditional course completion rates. Nelson (2006) compared course completion rates between online and traditional courses at Delaware Technical and Community College, Terry Campus. Her research found statistically significant differences in the course completion rates between online and traditional courses. Additional analysis showed that more students (23\%) withdrew from the online courses compared to the withdrawal rate in traditional courses (18.4\%).

Carr (2000) noted that some universities reported drop-out rates as high as $80 \%$ in online courses, but argued that course completion rates should not be compared across universities since universities report course completion rates differently. Some universities included students who dropped during the add/drop period while other universities did not report those instances. Without having a standard rule, a comparison across universities might not produce accurate results. Regardless of the ability to compare across universities, research into course completion rates is useful to university administrators tasked with determining class size and number of sections as well as those administrators responsible for assessing student learning outcomes for internal and external agencies (McLaren, 2004). 


\section{Student Performance}

Russell (2001) explored 355 research reports comparing student outcomes between different course delivery modes. The majority of the research indicated no statistically significant differences existed in student outcomes based on delivery mode. Clark (1994) stated that it was the teaching methods and not the delivery medium used that influenced learning. In all cases, Clark argued that the selection of course delivery mode should be an economic decision (1994).

Much research exists supporting Russell's (2001) work (Clark, 1994; Gagne \& Shepherd, 2001; McLaren, 2004). However, several studies have found statistically significant differences in student outcomes based on delivery type (Faux \& Black-Hughes, 2000; Paden, 2006; Shoenfeld-Tacher, McConnel, \& Graham, 2001). Paden found a statistically significant difference in student performance between online and traditional courses. Faux and Black-Hughes conducted research into student performance between different delivery modes of a social work course and found that a statistically significant difference existed between post-test scores by delivery mode. Additional analysis indicated that students in the online section did not perform as well as students in the traditional section.

\section{Course Completion by Discipline}

Several researchers found that certain disciplines were not suited for an online setting (Carnevale, 2003; Nelson, 2006; Noble, 2004; Paden, 2006; Smith, Heindel, \& TorresAyala, 2008). Lab science, health care (Carnevale, 2003), and mathematics (Smith et al., 2008) courses have all been identified as course disciplines that are not well-suited for online course delivery. Terry (2001) suggested that courses such as accounting, economics, computer information systems, marketing, and management were potentially more conducive to online course delivery.

Smith et al. (2008) compared attrition rates between mathematics-related courses and non mathematics-related courses and found higher attrition rates in the mathematicsrelated courses. Attrition in traditional mathematics-related courses was the same as the drop-out rates in non mathematics-related courses. The researchers suggested that "for online students, mathematics is not working as well as other disciplines online, and further, students' difficulties with mathematics relative to other disciplines are not as great as in the face-to-face modality" (p. 152).

Online course delivery has been a growing area in higher education (Allen \& Seaman, 2008). As universities continue to transition courses to online delivery, it is important to understand the impact on student performance and retention. Is student performance in online courses comparable to performance in traditional courses? Are there differences in course completion in online courses when compared to traditional courses? Are some disciplines more appropriate for online delivery? 


\section{Purpose and Objectives}

The purpose of the study was to compare course completion rates and student performance between online and traditional courses. The following research objectives were used to guide the study:

1. Determine if there was a statistically significant difference in the performance of students enrolled in online courses compared to students enrolled in traditional courses.

2. Determine if there was a statistically significant difference in the retention of students enrolled in online courses compared to students enrolled in traditional courses.

3. Determine if there was a statistically significant difference in the retention of students enrolled in online courses by course discipline.

\section{Methodology}

This study had a causal-comparative research design, using archival data for students enrolled at a small, regional, public, comprehensive university located in the southwest United States. Archival data was used to compare both course completion and student academic performance (measured by final course grade) between groups of students in online and traditional courses. This same approach was used to compare course completion of students enrolled in online courses by course discipline.

Causal-comparative designs do not allow for explicit finding of causation (Fraenkel \& Wallen, 2006), but do strongly suggest whether mode of instruction had a direct impact on student retention. Additionally, since causal-comparative design takes place after data were collected and without any manipulation or intervention, it allowed for the exploration of naturally occurring relationships between groups.

The population $(\mathrm{N}=319,153)$ for this research was student course experiences for students enrolled in all 16-week courses taught between fall 2004 and spring 2009. Summer semesters were excluded as they are not comparable in structure or design to a fall or spring course (Nelson, 2006). Online courses as defined by Allen and Seaman (2008) were those courses "in which at least 80 percent of the course content is delivered online" (p. 4). For the purpose of this research, online courses were defined as those courses designated in the target university's student records system with an online building designation. Traditional courses were defined by Allen and Seaman (2008) as courses "with no online technology used - content is delivered in writing or orally" ( $p$. 4). For the purpose of this research, traditional courses were defined as those courses designated in the student records system with a building code other than online and with an instruction code of "lecture." 
For objective one, a purposive sample was selected that consisted of all student course experiences for students who were enrolled in and completed courses taught in both an online and traditional lecture format by the same professor during the same semester and year $(n=5,477)$. The total number of distinct students enrolled in the courses from the sample was 4,120 .

For objective two, a purposive sample was selected that consisted of all student course experiences for students enrolled in courses taught in both an online and traditional lecture format by the same professor during the same semester and year ( $n=5,778)$. The total number of distinct students enrolled in the courses from the sample was 4,307 .

For objective three, the sample included all student course experiences for students enrolled in online courses taught consistently during each of the 16-week semesters between fall 2004 and spring $2009(\mathrm{n}=8,445)$. Of the 41 subject areas with courses delivered between fall 2004 and spring 2009, only 14 subject areas were delivered during each of the semesters between fall 2004 and spring 2009. The total number of distinct students enrolled in courses from the sample was 3,932.

Data for the research objectives were extracted from the student records system using the Oracle Structured Query Language (SQL). For objectives one and two, all courses taught during full 16-week semesters were identified and extracted into a temporary table. Using the temporary table as the research sample, a SQL statement was written to find all courses with both online and traditional sections taught by the same professor during the same semester and year. With the sample courses identified, course delivery mode, registration status, and final grade were extracted for all students enrolled in the sample courses. No student identifying information was included in the data extraction.

For objective one, a comparison of student academic performance, all students with a registration status code other than dropped or withdrawn were included in the sample. This objective was intended to measure academic performance, only students who completed the course were included. Student academic performance was measured by the final course grade.

For objective two, a comparison of course completion, all students enrolled in the sample courses were used. Students with a grade code of A, B, C, D, or F and registration status other than dropped or withdrawn were flagged as retained and all others were flagged as not retained.

For objective three, a comparison of online course completion by course discipline, data extracted included registration status, final grade, and course subject for all students enrolled in all online courses identified in the initial base course table. Course discipline was defined as the subject area a course was associated with for a particular college and department. Subject areas were designated by a four character abbreviation and assigned to all courses listed in the host institution's course catalog. 
Pearson's chi-square test was used to determine if statistically significant differences existed in retention or performance by mode of instruction. "Chi-square is the inferential technique used to determine statistical significance of a relationship" (Wallen \& Fraenkel, 2001, p. 530). An alpha level of .05 was set a priori to determine if an association existed between the independent variable - delivery mode - and the dependent variables retention and performance. For objective three, a chi-square test was calculated on all students enrolled in online courses to determine if there was a statistically significant difference in the expected and observed retention by course discipline.

\section{Results}

Objective one was to determine if a statistically significant difference existed in academic performance of students enrolled in online courses compared to students enrolled in traditional courses. A chi-square analysis was performed in SPSS to determine if there was a statistically significant difference in student performance between students enrolled in online courses and students enrolled in traditional courses. Students enrolled in online courses had the highest percentage of As at 34.6\% compared to students enrolled in traditional courses at 31.3\%. Table 1 displays the grade distribution by course delivery modality. The difference in performance was statistically significant, $\chi^{2}(4, N=5,477)=27.383, p<05$ (see Table 1 ).

Table 1

Contingency Table for Students' Academic Performance $(\mathrm{N}=5,744)$

\begin{tabular}{lllllll}
\hline Modality & $\mathrm{A}$ & $\mathrm{B}$ & $\mathrm{C}$ & $\mathrm{D}$ & $\mathrm{F}$ & Total \\
& $(\%)$ & $(\%)$ & $(\%)$ & $(\%)$ & $(\%)$ & \\
\hline Online & 631 & 562 & 296 & 141 & 195 & 1,825 \\
& $34.6 \%$ & $30.8 \%$ & $16.2 \%$ & $7.7 \%$ & $10.7 \%$ & \\
Traditional & 1,142 & 1,180 & 762 & 270 & 298 & 3,652 \\
& $31.3 \%$ & $32.3 \%$ & $20.9 \%$ & $7.4 \%$ & $8.2 \%$ & \\
Total & 1,773 & 1,742 & 1,058 & 411 & 493 & 5,477 \\
& $32.4 \%$ & $31.8 \%$ & $19.3 \%$ & $7.5 \%$ & $9.0 \%$ & \\
\hline
\end{tabular}

Note. $\chi^{2}=27.383$, critical value $=9.49$, d.f. $=4$

Objective two was to determine if there was a statistically significant difference in the retention of students enrolled in online courses compared to students enrolled in traditional courses. A chi-square analysis was performed in SPSS to determine if there 
was a statistically significant difference in course completion between students enrolled in online courses and students enrolled in traditional courses. Students enrolled in online courses had the lowest course completion rates at 93.3\% compared to students enrolled in traditional courses at 95.6\%. Table 2 displays the course completion distribution by course delivery modality. The difference in retention was statistically significant, $\chi^{2}(1, \mathrm{~N}=5,778)=14.132, \mathrm{p}<.05$ (see Table 2$)$.

Table 2

Contingency Table for Course Completion Rates $(\mathrm{N}=5,778)$

\begin{tabular}{llll}
\hline Modality & $\begin{array}{l}\text { Retained } \\
(\%)\end{array}$ & $\begin{array}{l}\text { Not retained } \\
(\%)\end{array}$ & Total \\
\hline Online & 1,825 & 132 & 1,957 \\
& $93.3 \%$ & $6.7 \%$ & \\
Traditional & 3,652 & 169 & 3,821 \\
& $95.6 \%$ & $4.4 \%$ & \\
Totals & 5,477 & 301 & 5,778 \\
& $94.8 \%$ & $5.2 \%$ & \\
\hline
\end{tabular}

Note. $\chi^{2}=14.132$, critical value $=5.99$, d.f. $=2$

Objective three was to determine if there was a statistically significant difference in the retention of students enrolled in online courses by course discipline. A chi-square analysis was performed in SPSS to determine if there was a statistically significant difference in students' course completion by course discipline. The 14 different disciplines included in the chi-square analysis were accounting, agricultural education, computer information systems, English, finance, general business, health, human resource management, management, marketing, physical education, psychology, reading, and special education. Finance had the lowest course completion rate at $82.2 \%$ compared to reading with the highest retention rate at $98.2 \%$. The difference in retention by course discipline was statistically significant, $\chi^{2}(13, N=8,445)=96.974, p$ $<.05$ (see Table 3). 
Table 3

Contingency Table for Course Completion by Course Discipline $(\mathrm{N}=8,445)$

\begin{tabular}{lrccc}
\hline Modality & Retained & Not retained & \% Retained & \multicolumn{1}{c}{ Total } \\
\hline Computer information systems & 1,311 & 118 & 91.7 & 1,429 \\
General business & 1,187 & 88 & 93.1 & 1,275 \\
Management & 1,000 & 81 & 92.5 & 1,081 \\
Psychology & 924 & 93 & 90.9 & 1,017 \\
English & 654 & 63 & 91.2 & 717 \\
Physical education & 450 & 23 & 95.1 & 473 \\
Marketing & 417 & 33 & 92.7 & 450 \\
Special education & 386 & 16 & 96.0 & 402 \\
Health & 339 & 11 & 96.9 & 350 \\
Human resource management & 278 & 40 & 87.4 & 318 \\
Finance & 245 & 53 & 82.2 & 298 \\
Agricultural education & 271 & 22 & 92.5 & 293 \\
Accounting & 151 & 24 & 86.3 & 175 \\
Reading & 164 & 3 & 98.2 & 167 \\
Totals & 7,777 & 668 & 92.1 & 8,445 \\
\hline
\end{tabular}

Note. $\chi^{2}=96.974$, critical value $=22.36$, d.f. $=13$

Conclusions and Recommendations

The growth rate of student enrollments in online courses is outpacing the growth rate of the total higher education student population (Allen \& Seaman, 2008). Research on the course completion rates in online education is mixed. Some research has found course completion in online courses was as good as or better than in traditional courses (Roach, 2002). Other researchers have found that traditional courses have higher course completion rates when compared to online equivalents (Brady, 2001; Carr, 2000; Simpson, 2003).

Course completion and student performance has financial impacts on students as well as the university. The THECB (2008) proposed a shift in formula funding from attempted to completed semester credit hours. If retention and completion in online courses is lower than the traditional classroom setting, the host university could potentially lose a portion of state funding. Understanding where retention in online courses is a problem will allow the host university to take corrective action in order to increase retention and student success in online courses. Additionally, the Texas Administrative Code dictates that a university "shall not submit for formula funding any 
hours for a course that is the same or substantially similar to a course that the student previously attempted for two or more times at the same institution" ([TAC], Title 19, Part 1, Rule 13.105, 2005). To compensate for the loss of state funding, the university could charge tuition up to the out-of-state tuition rates for the course.

Objective one sought to determine if statistically significant differences existed in student performance between online and traditional courses. A chi-square analysis on the dataset indicated that a statistically significant difference did exist in the student performance between online and traditional courses. This finding supports previous research on student performance in online courses (Faux \& Black-Hughes, 2000; Paden, 2006; Shoenfeld-Tacher, McConnel, \& Graham, 2001). Additional observation of the grade frequencies found a higher percentage of As, Ds, and Fs in online courses, while traditional courses had a higher percentage of Bs and Cs. Shoenfeld-Tacher et al. found student academic performance as measured by a post-test in an online science course was significantly different and superior to student performance in the traditional course section. Paden found that student academic performance in an introductory math course was significantly different between online and traditional delivery. Contrary to what Shoenfeld-Tacher et al. found, Paden noted academic performance of students enrolled in the traditional section of the introductory math course was superior to students enrolled in the online section.

With regard to objective two, statistically significant differences did exist in course completion rates between online and traditional course delivery. This finding supports research conducted by McLaren (2004), Paden (2006), and Roach (2002) who found differences in course completion rates between online and traditional courses. Additional analysis indicated that students enrolled in online courses had a lower course completion rate (93.3\%) than students enrolled in traditional courses (95.6\%). This supports research by Paden who found that traditional course delivery had a higher retention rate compared to online delivery for students enrolled in an introductory math course. Nelson (2006) found statistically significant differences in student retention rates between online and traditional course delivery.

With regard to objective three, statistically significant differences existed in course completion rates by course discipline. Additional observations supported previous research that suggested some disciplines may not be well-suited to online delivery (Carnevale, 2003; Nelson, 2006; Noble, 2004; Paden, 2006; Smith, Heindel, \& TorresAyala, 2008). Course completion varied by discipline with reading having the highest rate at $98.2 \%$ and finance with the lowest at $82.2 \%$. Nelson examined course completion rates for nine disciplines and found that no statistically significant differences existed for seven of the disciplines. However, statistically significant differences did exist in criminal justice and psychology and Nelson suggested that these course disciplines might not be conducive to online delivery. Smith et al. (2008) compared online and traditional course completion rates in mathematics courses and found lower retention rates in online mathematics courses. The researchers suggested that mathematics might not be appropriate for online delivery. 
The research was conducted using archival data from the host institution's student record system. No data was available on student perceptions of the courses or student aptitude with the technology used for course delivery. Additional student characteristics such as age, gender, ethnicity, classification, major, and experience with online course delivery were not evaluated as part of this research. What type of student is likely to succeed in online courses? Does experience with the technology lead to greater course completion and improved student performance in online courses? More research into student characteristics could help identify possible variables to predict student success in online courses. 


\section{References}

Allen, I. E., \& Seaman, J . (2008). Staying the course: Online education in the United States, 2008. Needham, MA: The Sloan Consortium.

Berger, J . B., \& Lyon, S. C. (2005). Past to present a historical look at retention. In A. Seidman (Ed.), College student retention formula for student success (pp.1-29). Westport, CT: Prager.

Brady, L. (2001). Fault lines in the terrain of distance education. Computers and Composition, 18(4), 347-358.

Carnevale, D. (2003). The virtual lab experiment: Some colleges use computer simulations to expand science offerings online. The Chronicle of Higher Education, 49(21), A30.

Carr, S. (2000). As distance education comes of age, the challenge is keeping the students. Chronicle of Higher Education, 46(23), A39-A41.

Clark, R. (1994). Media will never influence learning. Educational Technology Research and Development, 42(2), 21-29.

Faux, T. L., \& Black-Hughes, C. (2000, J uly). A comparison of using the internet versus lectures to teach social work history. Research on Social Work, 10(4), 454-466.

Fraenkel, J . R, \& Wallen, N. E. (2006). How to design and evaluate research in education (6 $6^{\text {th }}$ ed.). New York, NY: McGraw-Hill.

Gagne, M., \& Shepherd, M. (2001, April). A comparison between a distance and a traditional graduate accounting class. T.H.E. J ournal. Retrieved from http:// thejournal.com/Articles/2001/ 04/ 01/A-Comparison-Between-aDistance-and-a-Traditional-Graduate-Accounting-Class.aspx

Harasim, L. (2000). Shift happens: Online education as a new paradigm in learning. Internet and Higher Education, 3, 41-61.

McLaren, C. H. (2004, Spring). A comparison of student persistence and performance in online and classroom business statistics experiences. Decision Sciences J ournal of Innovative Education, 2(1), 1-10.

Nelson, P. F. (2006). Student retention in online education at the community college. Retrieved from ProQuest. (UMI 3222374)

Noble, J . V. (2004). For science and math, skip the online course. Communications of the Association for Computing Machinery, 47(10), 12-13. 
Paden, R. R. (2006). A comparison of student achievement and retention in an introductory math courses delivered in online, face-to-face, and blended modalities. Retrieved from ProQuest. (UMI 3237076)

Palloff, R., \& Pratt, K. (2003). The virtual student. San Francisco, CA: J ossey-Bass.

Roach, R. (2002). Staying connected: Getting retention right is high priority for online degree programs. Black Issues in Higher Education, 19(18), 22-25.

Russell, T. L. (2001). The no significant difference phenomenon: A comparative research annotated bibliography on technology for distance education. Raleigh, NC: IDECC.

Shoenfeld-Tacher, R., McConnel, S., \& Graham, M. (2001). Do no harm-A comparison of the effects of on-line vs. traditional delivery media on a science course. J ournal of Science Education and Technology, 10(3), 257-265.

Simpson, O. (2003). Student retention in online, open, and distancelearning. London, UK: Kogan Page.

Smith, G. G., Heindel, A. J ., \&Torres-Ayala, A. T. (2008). E-learning commodity or community: Disciplinary differences between online courses. Internet and Higher Education, 11, 152-159.

Terry, N. (2001). Assessing enrollment and attrition rates for the online MBA. T.H.E. J ournal, 28(7), 64-68.

Texas Higher Education Coordinating Board. (2008). Formula funding recommendations for the 2010-2011 biennium. Austin, TX: Office of External Relations.

Texas Secretary of State. (2005). Texas administrative code. Retrieved from http://info.sos.state.tx.us/pls/pub/ tacctx\$.startup

Waschull, S. B. (2001). The online delivery of psychology courses: Attrition, performance, and evaluation. Teaching of Psychology, 28(2), 143-147.

\section{Athabasca University $\mathbf{a}$}

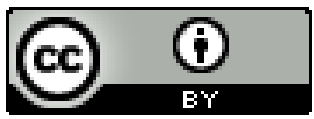

